\title{
Heurística do Medo: mídia e meio ambiente na sociedade de risco $^{1}$
}

\author{
Leonel Azevedo de AGUIAR ${ }^{2}$ \\ Pontifícia Universidade Católica do Rio de Janeiro, Rio de Janeiro, RJ \\ Ângela SCHAUN ${ }^{3}$ \\ Universidade Presbiteriana Mackenzie, São Paulo, SP
}

\begin{abstract}
RESUMO
Esse ensaio discute como as notícias sobre as catástrofes ecológicas globais passaram a ter amplo destaque na mídia e demonstra de que modo esses discursos jornalísticos vinculam a crise do meio ambiente a uma heurística do medo, na qual o signo da negatividade esvazia a possibilidade da ação política. Essa pesquisa foi realizada a partir do mapeamento das formações discursivas sobre a crise ambiental enunciada nas primeiras páginas de dois jornais diários de circulação no Rio de Janeiro ( $O$ Globo e Jornal do Brasil). O trabalho conclui que as formações discursivas presentes nos jornais pesquisados são reforçadas pelo contexto social de fruição das mensagens, já que o público-receptor encontra-se imerso em uma sociedade marcada pelos riscos globais.
\end{abstract}

Palavras-chave: mídia e meio ambiente; heurística do medo; jornalismo; sociedade de riscos.

\section{ABSTRACT}

This essay discusses how the news about the global ecological disasters have gained wide prominence in the mainstream media. Also it demonstrates how these journalistic discourses link the environmental crises to a heuristics of fear, in which the sign of negativity empties the possibility of political action. This survey was conducted based on the mapping of the discussions about the environmental crisis, published in the first pages of two daily newspapers in Rio de Janeiro/Brazil (O Globo and Jornal do Brasil). The paper concludes that the discursive formations presented in the surveyed newspapers are reinforced by the social context of the enjoyment of the messages, since the receptor-public is immersed in a society marked by global risks.

Keywords: media and environment; heuristics of fear; journalism; risky society.

\footnotetext{
1 Trabalho apresentado à segunda edição da Revista Ação Midiática - Estudos em Comunicação, Sociedade e Cultura, publicação ligada ao Programa de Pós-Graduação em Comunicação e Sociedade, da Universidade Federal do Paraná.

${ }^{2}$ Professor do Programa de Pós-graduação em Comunicação e coordenador do Curso de Comunicação Social da PUC-Rio. Doutor e Mestre em Comunicação e Cultura (UFRJ). E-mail: laaguiar@uol.com.br

${ }^{3}$ Professora Adjunto I e pesquisadora do Curso de Jornalismo do Centro de Comunicação e Letras da Universidade Presbiteriana Mackenzie/São Paulo. Doutora em Comunicação e Cultura (UFRJ). E-mail: angelaschaun@ yahoo.com
} 


\section{Introdução}

As notícias relacionadas à desordem ecológica global vêm recebendo um amplo destaque nos meios de comunicação de massa, especialmente nos jornais diários. Essas mensagens jornalísticas, entretanto, constroem uma produção de sentido dos problemas ambientais que vincula esta temática ao princípio da responsabilidade (JONAS, 2006), no qual a ação da sociedade acaba sendo impulsionada por uma pedagogia política centrada no sentimento do medo coletivo. Se concordarmos que uma das características da sociedade contemporânea é a produção de riscos globais (BECK, 1992) de consequiências cataclísmicas - entre os quais, o aquecimento do planeta Terra e o enfraquecimento da camada de ozônio pela emissão de gases poluentes, além das "tecno-epidemias" (BECK, 1994), isto é, as doenças resultantes de tecnologias que poluem a água, o ar, o solo e os alimentos -, podemos apontar que tais riscos, além de serem inerentes ao processo de mundialização do capitalismo, determinam os valores contemporâneos sob a negatividade de uma heurística do medo ${ }^{4}$.

Esse ensaio teórico visa discorrer historicamente sobre os discursos produzidos pela mídia jornalística em relação às questões ambientais. O texto parte da discussão levantada por Hans Jonas (2006) sobre a ética para a sociedade tecnológica e conclui discordando do filósofo alemão - que o princípio da responsabilidade atua como imperativo do dever moral indutor de um sentimento do medo coletivo e não como escolha ética. Apesar de reconhecer que a irredutibilidade dos riscos globais implica no fim das certezas dadas pela ciência (PRIGOGINE, 1996) e seus instrumentos de controle típicos da Modernidade, o princípio da responsabilidade proposto por Jonas acaba se impondo como "deve ser" (isto é, dever moral) ao invés de "pode ser" (ou seja, opção ética). Tal procedimento político-pedagógico não só se materializa através da produção dos textos jornalísticos sobre os problemas do meio ambiente, mas, simultaneamente, a formação discursiva sobre a crise ambiental construída pela sociedade - instâncias governamentais, entidades ambientalistas, instituições de pesquisa - apresenta como, principal característica, a marca da heurística do medo.

Ao realizarmos um levantamento das manchetes e chamadas das primeiras páginas sobre os problemas ambientais em dois jornais do Rio de Janeiro, no período

\footnotetext{
${ }^{4}$ Segundo Jonas (2006, p. 71), a filosofia da moral tem que consultar "o nosso medo antes do nosso desejo e, embora a heurística do medo não seja a última palavra na procura do bem, é uma palavra muito útil”.
} 
situado entre 1992 e 2001, podemos afirmar que o processo de globalização produziu um discurso jornalístico marcado pela enunciação de que os riscos ecológicos também se tornaram globais. O período estudado está delimitado por dois eventos de caráter mundial: a Conferência das Nações Unidas sobre Meio Ambiente e Desenvolvimento, realizada por iniciativa da Organização das Nações Unidas, em 1992, no Rio de Janeiro, e o ano que antecede a Cúpula Mundial sobre Desenvolvimento Sustentável, ocorrida em 2002, em Johannesburgo, na África do Sul. O corpus de análise compõe-se de 1.322 textos jornalísticos, manchetes e chamadas de capa que abordam assuntos sobre meio ambiente.

Como esse ensaio não tem a finalidade de dar destaque à pesquisa quanto às manchetes e chamadas de capa, já apresentada em outros artigos (AGUIAR, 2003; 2004; 2010), selecionamos, apenas alguns exemplos nas primeiras páginas dos jornais $O$ Globo e Jornal do Brasil, com o objetivo de evidenciar as questões teóricas que são aqui discutidas:

- "ONU aponta destruição ambiental sem precedentes"5;

- "Civilização desaparecerá em 20 anos"";

- "Desertificação já ameaça vida na Terra"7;

- "Temos que agir para salvar a Terra"

- "Chefes do mundo assumem na Rio-92 o compromisso de salvar a Terra"9;

- "Terra está em perigo, dizem 1575 cientistas"10;

- "ONU mostra que saúde do planeta piorou"11;

- "Especialistas listam tragédias ambientais que podem ser causadas pelo aquecimento do planeta"12;

- "Aquecimento global começa a derreter geleiras"13;

- "Caos no clima trará fome"14;

- "Estudo lista os perigos do aquecimento global"15;

- "Aumenta o risco de extinção global"16;

\footnotetext{
${ }^{5}$ Jornal do Brasil, Rio de Janeiro, 08 mai 1992.

${ }^{6}$ Jornal do Brasil, Rio de Janeiro, 18 mai 1992. A manchete refere-se a um trecho da entrevista feita com Lester Brow, editor do relatório Situação do Mundo.

${ }^{7}$ Jornal do Brasil, Rio de Janeiro, 29 mai 1992.

${ }^{8}$ Jornal do Brasil, Rio de Janeiro, 31 mai 1992. A manchete remete a um trecho da entrevista realizada com Maurice Strong, secretário-geral da ONU para a Conferência Rio-92.

${ }^{9}$ Jornal do Brasil, Rio de Janeiro, 13 jun 1992.

${ }^{10}$ Jornal do Brasil, Rio de Janeiro, 19 nov 1992.

${ }^{11}$ Jornal do Brasil, Rio de Janeiro, 10 dez 1992.

${ }^{12}$ O Globo, Rio de Janeiro, 16 out 2000.

${ }^{13}$ O Globo, Rio de Janeiro, 07 dez 2000.

${ }^{14}$ O Globo, Rio de Janeiro, 20 fev 2001.

${ }^{15}$ O Globo, Rio de Janeiro, 02 mai 2001.
} 
- "Caos no clima aumenta violência de furacões"17.

A escolha pelas manchetes justifica-se pela análise empreendida por Rodrigues (1997, p. 108) em relação às figuras dos títulos jornalísticos, na qual aponta que, por causa do processo de figuração, as manchetes "se constituem em texto dentro do texto" fazendo, ao mesmo tempo, "ver e esconder o texto para que dirigem o olhar do leitor". Elegemos duas questões para pensar como os riscos globais, resultantes da mundialização do capitalismo, marcam os valores contemporâneos sob a ótica da negatividade - a partir de uma pedagogia política centrada no sentimento do medo coletivo - e como essa perspectiva está expressa nos discursos jornalísticos. As duas questões sintetizam-se nas seguintes perguntas, típicas do método genealógico de Foucault (1990): para que ${ }^{18}$ os desastres ambientais e as catástrofes ecológicas merecem uma visibilidade midiática cada vez maior? Para que a mídia produz um discurso aproximando o princípio da responsabilidade de uma ação política impulsionada pelo medo?

Como na perspectiva foucaultiana todo discurso é o eco lingüístico da articulação entre saber e poder, se torna imprescindível uma análise genealógica do poder contemporâneo, que descreva um regime de discursividade e investigue a relação existente entre os grandes tipos de discursos e as condições históricas e políticas de seu aparecimento (FOUCAULT, 1996).

\section{Perspectiva teórica}

É a "ordem do discurso" que estabelece, para Foucault (1996), as possibilidades de organização do real. Esta ordenação, além de possuir uma função normativa e reguladora, age por meio da produção de saber, de estratégias de poder e de práticas discursivas. Tomando as noções teóricas foucaultianas, podemos afirmar: discurso não é, apenas, o lugar onde o desejo se manifesta ou se oculta, mas é, antes de tudo, o objeto do desejo. Mais ainda: o discurso traduz mais do que as lutas políticas, pois se torna, principalmente, o poder pelo qual se deseja lutar para exercê-lo; portanto, é preciso pensar o discurso como o lugar do exercício do poder.

Para Foucault, é justamente no discurso que se articulam poder e saber. Sendo assim, é preciso conceber o discurso como "uma série de segmentos descontínuos, cuja

\footnotetext{
${ }^{16}$ O Globo, Rio de Janeiro, 09 mai 2001.

${ }^{17}$ O Globo, Rio de Janeiro, 20 jul 2001.

${ }^{18}$ Segundo Foucault $(1977 ; 1979 ; 1980)$, a partir de Nietzsche, a pergunta para a construção teórica passa a ter uma perspectiva genealógica: "para quê?" é uma pergunta que escapa ao controle da produção da verdade.
} 
função tática não é uniforme nem estável" (FOUCAULT, 1980, p. 95). Admitir a complexidade e a instabilidade de um jogo em que o discurso pode ser, simultaneamente, instrumento e efeito de poder e, também, ponto de resistência e ponto de partida de uma estratégia oposta é aceitar a regra da polivalência tática dos discursos. "O discurso veicula e produz poder; reforça-o, mas também o mina, expõe, debilita e permite barrá-lo" (idem, 96). Ou seja, os discursos produzem os efeitos recíprocos de poder e saber. Também devemos perguntar qual é a conjuntura e a correlações de forças que tornam imprescritível a utilização do discurso como articulação entre poder e saber.

Os discursos são, nesse sentido, blocos táticos no campo das correlações de força: os efeitos recíprocos de poder e saber proporcionam sua produtividade tática. Já a sua integração estratégica dos discursos implica na produção dos efeitos de verdade. "Vivemos em uma sociedade que produz e faz circular discursos que funcionam como verdade, que passam por tal e que detêm poderes específicos" (FOUCAULT, 1979, p. 231). Assim, além da vontade de saber e da vontade de poder que atravessam os discursos, a vontade de verdade constitui e, simultaneamente, é constituída pelos discursos. Desse modo, o conceito de ideologia - e, por conseguinte, o de manipulação ideológica - pode ser descartado por estar vinculado a ideia nostálgica de um saber transparente e livre do erro e da ilusão. Em seu conceito moderno, a ideologia apresenta-se em oposição à verdade; ou melhor, opõe-se a um discurso capaz de revelar a verdade, enquanto a ideologia representa o falso. Além disso, a ideologia é uma produção discursiva realizada por um sujeito com o objetivo de impedir o conhecimento da verdade. O que se deve observar, segundo Foucault, é como os efeitos de verdade são produzidos dentro dos discursos que, em si mesmos, não são falsos nem verdadeiros. O que o método foucaultiano de análise do discurso ${ }^{19}$ propõe estudar é o "regime da verdade" enquanto um componente efetivo na constituição das práticas discursivas.

Seguindo essas proposições foucaultianas, podemos entender a "verdade" como um conjunto de procedimentos regulados para a produção, distribuição e funcionamento dos discursos. "A verdade está circularmente ligada a sistemas de poder que a produzem e a confirmam, e a efeitos de poder que ela induz e que a reproduzem" (FOUCAULT, 1979, p. 14). Os métodos foucaultianos concentram suas análises exatamente nas práticas culturais em que o poder e o saber se cruzam. Dentre essas práticas, ele destaca

\footnotetext{
${ }^{19}$ Em Foucault, a análise do discurso apresenta-se por duas metodologias: a arqueologia do saber (ver FOUCAULT, 1996; 1997; 1999) e a genealogia do poder (ver FOUCAULT, 1977; 1979; 1980). O método arqueológico procura elucidar as condições de aparecimento histórico dos discursos, enquanto o método genealógico articula produção de saber com relação de poder, formação discursiva e efeito de verdade.
} 
o jornalismo - “invenção fundamental do século XIX” (FOUCAULT, 1979, p. 224) - e ressalta a importância da materialidade dos meios de comunicação, comandados por interesses econômicos e políticos que obedecem a mecanismos do poder. Em síntese: se todo discurso é "constituído por um número limitado de enunciados para os quais podemos definir um conjunto de condições de existência" (FOUCAULT, 1997, p. 135), o discurso jornalístico, por sua vez, - além de produzir e ser produzido por relações de poder-saber e pela vontade de verdade como qualquer outra ordem discursiva - é instituído por um conjunto de enunciados que se apóia em um mesmo sistema de formação discursiva.

Aos métodos de análise do discurso de Foucault, devemos buscar determinados conceitos de Guattari, para pensar que a crise ambiental coloca em jogo o modo humano de viver na Terra, face à alteração promovida pela tecno-ciência nas paisagens sociais e naturais. Neste quadro de complexidade, a problemática ecológica deve pertencer simultaneamente ao registro do meio ambiente, das relações sociais e da produção de subjetividades. A recusa em enfrentar as degradações nesses três domínios, separando a crise ecológica das questões relativas ao socius e a psiquê - tal como realiza a mídia jornalística -, confina a questão ecológica aos limites da ciência como mero empreendimento em busca da eficácia técnica para o gerenciamento do meio ambiente.

Guattari (1990) denominou de "ecosofia" ao campo de articulação das três ecologias, englobando a ecologia ambiental, a ecologia social e a ecologia mental. É exatamente esta concepção ecosófica que põe em questão o conjunto das relações de poder e da produção de subjetividades. A referência ético-estética dos valores ecosóficos indica possibilidades de recomposição da práxis humana nos mais diversos domínios da vida cotidiana.

A articulação entre ética e estética promovida pelo registro das três ecologias nos permite pensar as implicações de uma perspectiva ecosófica sobre a concepção da subjetividade. Também possibilita colocar a comunicação midiática como campo político hegemônico da atualidade, por funcionar como máquina de produção de subjetividades moduladas pelo capitalismo global. A tarefa da ecologia social consiste em fazer atravessar a sociedade capitalista da era da mídia para uma era pós-mídia, onde os grupos-sujeito serão capazes de uma reapropriação da mídia para geri-la em um processo de singularização. Já à ecologia mental cabe produzir linhas de rupturas no projeto de uniformização midiática, reinventando a relação com o corpo, o tempo e os espaços da vida cotidiana. É nesta perspectiva que se torna possível colocar a mídia no 
centro da crise ecológica contemporânea, com a potencialização do conceito de ecosofia.

A adoção de uma ética ecosófica implica em distinguir os agregados imaginários de massa dos agenciamentos coletivos de enunciação, opondo os mecanismos de repetição vazia aos maquinismos vivos "autopoiéticos” (VARELA, 1989). Discutir as relações entre comunicação midiática e crise ecológica contemporânea é fazer do diagrama das três ecologias uma "caixa de ferramentas" teóricas para pensar questões contemporâneas. A perspectiva ecosófica engendra novos universos de referência e novos territórios existenciais, diferentes da visão reducionista correlativa ao primado da informação como trânsito incessante nos sistemas midiáticos.

Situado o quadro de discussão teórica privilegiado nesse trabalho, vamos, a seguir, mapear os cenários históricos em que se desenvolvem as formações discursivas sobre a crise do meio ambiente.

\section{Formações discursivas}

$\mathrm{Na}$ década de 1960, as formações discursivas enunciavam os problemas ambientais como resultantes de uma crise de participação. A luta do movimento ecológico centrava-se no acesso aos recursos naturais, com a distribuição eqüitativa para os setores socialmente excluídos, e a vertente da Ecologia Política - surgida naquela mesma década - tinha, como plataforma, propostas exclusivamente políticas para superar os problemas ambientais. Entretanto, justamente por estar ainda no quadro de um sistema de pensamento tipicamente moderno, é que esta vertente elegeria a ecologia - enquanto ciência - para se tornar o paradigma da superação dos impasses da Modernidade.

Nos anos 1960, os riscos ambientais pelo uso de agrotóxicos na agricultura e os efeitos perigosos para o meio ambiente e os consumidores começam a ser divulgados para o grande público. Primavera Silenciosa, da bióloga Rachel Carson, só no ano de seu lançamento, em 1962, atinge a marca de 500 mil exemplares vendidos. Pela primeira vez, uma obra com discussões científicas ultrapassou o círculo restrito da comunidade de cientistas e técnicos especialistas, alcançando importante repercussão junto à opinião pública ${ }^{20}$.

Já na década de 1970, a crise ambiental deixa de ser enunciada como uma crise

\footnotetext{
${ }^{20}$ Podemos ver, nesse caso, uma luta pela produção de sentido: enquanto a indústria química denomina esses produtos de fertilizantes ou defensivos agrícolas, o movimento ecológico prefere agrotóxicos ou veneno. Ver Carson (1964) e também Bull e Hathaway (1986).
} 
de participação, na qual a temática ecológica estava marcada pela mobilização política de poucos e pequenos grupos sociais e por um silêncio dos meios de comunicação de massa em torno do tema da degradação do meio ambiente. Um novo movimento de massas surge e a questão ambiental começa a encontrar seu caminho na agenda das políticas públicas. Nessa perspectiva, podemos citar - como exemplo de massificação das lutas ecológicas - a instituição do Dia da Terra, que veio a se tornar a maior manifestação em defesa do meio ambiente até então realizada nos Estados Unidos. Na data programada, 22 de abril ${ }^{21}$ de 1970, foram realizados comícios e palestras, simultaneamente, em dez mil colégios e em 1.500 faculdades, além de atos públicos em Nova York e em Washington. As estimativas apontam a mobilização de dois milhões de participantes. Os eventos resultaram em reportagens de capa e manchetes de jornais e de revistas como a Time e a Life.

Depois da publicação do relatório do Clube de Roma/Instituto de Tecnologia de Massachusetts (MIT) - intitulado Os Limites do Crescimento, propondo o "crescimento zero" da economia - e da Conferência das Nações Unidas sobre o Meio Ambiente Humano, realizada em 1972, em Estocolmo, as formações discursivas sobre a crise do meio ambiente assumem, portanto, o enunciado de uma crise de sobrevivência. A crise ambiental passou a ser enunciada, então, como um problema de escassez, já que os cientistas e as autoridades governamentais afirmavam existir limites insuperáveis para a exploração e o uso dos recursos naturais, sendo imprescindível frear a expansão material ilimitada da sociedade. Houve, na época, um forte consenso a favor de limitar o crescimento da economia e da população, unindo ecologistas radicais da revista The Ecologist, cientistas - a maioria da área das ciências naturais - e empresários, além de políticos.

A formação discursiva sobre o meio ambiente, nos anos 1970, enuncia a transformação que vem acontecendo no Ocidente: a emergência de valores pósmaterialistas (MILBRATH, 1984). A crítica dos ecologistas vai apontar que o projeto desenvolvimentista da sociedade moderna está baseado em um sistema de valores materialistas, de tal modo que se reduz a finalidade da vida dos homens à acumulação infindável de bens materiais. Nesse modelo de enunciação da crise ambiental, o problema ecológico decorre da ideologia do progresso, que considera a base material -

\footnotetext{
${ }^{21}$ A data escolhida para o Dia da Terra causou muito protesto de políticos republicanos nos Estados Unidos, pois o dia 22 de abril é o aniversário de Lênin (Vladimir Ilich Ulianov, nascido em 1870), líder da revolução comunista na Rússia e um dos idealizadores do Estado soviético. A data foi proposta pelo senador Gaylord Nelson, a partir de uma pressão social pela criação da Agência de Proteção Ambiental.
} 
isto é, a natureza - desse estilo de desenvolvimento como inesgotável. Este desenvolvimentismo, cuja finalidade é o crescimento ilimitado, entende que esta base material é infinita do ponto de vista dos recursos naturais e, também, na sua capacidade de suportar as atividades poluidoras e seu resultado, a poluição ambiental.

Na década seguinte, os anos de 1980, a formação discursiva sobre a crise ambiental assume a figura da crise cultural. A crise do meio ambiente passa a ser enunciada como o momento oportuno para superar a racionalidade instrumental e a ética de valores materialistas que construíram a Modernidade. Dentro dessa ordem discursiva, o principal avanço da problemática ambiental na direção de uma articulação entre ética e política pode ser apontado para publicação do relatório Nosso Futuro Comum, pela Comissão Mundial sobre Meio Ambiente e Desenvolvimento da ONU, em 1987. Além de um esforço para a obtenção do consenso mundial sobre questões de meio ambiente e desenvolvimento, o relatório pretendeu ser uma agenda global para mudança, propondo o conceito de desenvolvimento sustentável enquanto um estilo de desenvolvimento econômico que leva em conta a sustentabilidade global do meio ambiente, de modo a atender às necessidades do presente sem comprometer a possibilidade das gerações futuras atenderem as suas próprias necessidades. Constituído por três figuras do consenso - crescimento econômico, equidade social e equilíbrio ecológico -, esse conceito assegura amplos espaços de divulgação nos meios de comunicação de massa exatamente por permitir acomodar os mais diversos interesses empresariais e governamentais. Apesar de reconhecer a complexidade e a interdependência da problemática ambiental, o conceito de desenvolvimento sustentável está vinculado a um dever moral, implicando em uma responsabilidade da sociedade frente ao meio ambiente.

Naquele momento, a questão ambiental adquiriu plena visibilidade nos meios de comunicação de massa. Um exemplo: conforme sempre realiza no seu último número anual, a revista Time elegeu - como "personalidade do ano" de 1988 - um "novo sujeito histórico" que vinha se destacando enquanto inusitado protagonista do noticiário jornalístico - o planeta Terra. Para determinados pesquisadores (VIOLA e LEIS, 1991) da temática ambiental, este fato jornalístico pode ser entendido como uma ruptura nas ordens discursivas sobre os desequilíbrios ecológicos globais que ameaçam a biosfera.

Entretanto, preferimos abordar esse caso paradigmático por outra perspectiva. Para nós, o que está em questão é saber para que um meio de comunicação de massa nesse caso, uma revista informativa pertencente a uma mega-empresa norte-americana, 
que funciona como "agenciamento coletivo de enunciação" (GUATTARI, 1990, p. 46) voltado para a produção de subjetividades adequadas à atual etapa do imperativo consumista do capitalismo - propõe uma mudança urgente no modelo de desenvolvimento e nos atuais modos de vida para solucionar a crise ambiental. Morin e Kern (1995) apontam que foi exatamente o consumismo, enquanto ideologia resultante do pensamento materialista moderno, que se transformou na forma hegemônica de realização do capitalismo a partir da segunda metade do século XX e acarretou a crise do meio ambiente em âmbito global, ultrapassando os até então níveis locais dos desequilíbrios ambientais.

A partir desse exemplo, outras questões instigantes podem ser discutidas nesta relação entre os meios de comunicação de massa, as formações discursivas sobre a crise ambiental e o movimento ecológico. Eis algumas interrogações. Quais são as condições de possibilidade para que um meio de comunicação de massa, que funciona como um dispositivo atrelado à ideologia do consumismo, entenda o planeta Terra como "pátria da humanidade" - conforme Morin e Kern (1995) - e uma "pessoa" - de acordo com Roszak (1981) - portadora de direitos? A invenção desse novo sujeito da História - o planeta Terra - significa que está em curso a desintegração de um modelo de sociedade - a sociedade moderna - que só considera o homem como o único sujeito de direito?

\section{Crise ambiental global}

Na década de 1990, a formação discursiva sobre a crise ambiental emerge como um risco planetário, vinculando-se ao processo de globalização do capitalismo, ao seu modelo de sociedade e a uma produção de subjetividade centrada na ideologia do individualismo e no racionalismo técnico-científico. Ou seja, a crise ecológica do meio ambiente não é mais enunciada como o resultado de uma explosão demográfica ou de uma depleção dos recursos naturais, mas é engendrada pelo discurso de uma crise global de civilização, isto é, de um modelo de sociedade que se tornou globalizado. A crise ambiental é global porque abrange toda a humanidade e seu lugar de habitação, a biosfera. Essa ordem discursiva, que se consolida ao longo de toda esta década de 1990, aponta que a problemática desencadeada pela crise global da biosfera ultrapassa as abordagens teóricas que entendem o movimento ecológico enquanto expressão dos novos movimentos sociais, campo político contemporâneo de formulação de uma crítica ao sistema capitalista e de uma ética com valores contrapostos aos da ordem social 
moderna, inclusive aquela orientação valorativa dos movimentos sociais tipicamente modernos, como o sindicalismo.

Esse enunciado também assinala que há um afastamento do movimento ecológico em relação aos novos movimentos sociais: os movimentos de promoção e garantia dos direitos das mulheres, dos negros, dos indígenas, dos jovens, dos loucos possuem como referência um sujeito histórico preciso, que se expressa na imanência do corpo - demandando, portanto, ações políticas específicas para questões singulares. Em outra direção política, o movimento ecológico aposta que não se chegou ao "fim da História" $^{22}$ e almeja a transformação ampla e radical da sociedade capitalista em sua totalidade. No movimento ecológico, a falta de definição precisa de um sujeito histórico é entendida como a expressão "de sua posição privilegiada de novo patamar, a partir do qual pode-se repensar a trajetória da civilização" (SADER, 1992, p. 139). Na associação da crise ambiental como uma crise de civilização em nível planetário, englobando toda a humanidade, em suas diversas formas de sociedades, o ecologismo aponta para um projeto totalizante que se afasta das propostas singularizantes dos novos movimentos sociais, afirmadoras da primazia do particular sobre o geral. Isto é: se a proposta política típica da Modernidade era universalizante e geral, a perspectiva contemporânea dos novos movimentos sociais não pretende realizar nenhum projeto de síntese totalizante e, sim, afirmar a possibilidade de uma consciência fragmentada. O movimento ecológico, entretanto, "ao acreditar que tudo se liga a tudo e ao proclamar a totalidade como a medida do homem" (CRESPO, 1997, p. 210), marca sua diferença em relação aos movimentos sociais que enfatizam a fragmentação da consciência política e o reconhecimento da impossibilidade de projetos totalizantes como uma das principais características do campo político contemporâneo.

Ter, portanto, como premissa o entendimento de que a sociedade moderna em sua atual etapa de integração mundial é insustentável, segundo parâmetros sócioambientais formulados pelo movimento ecológico, significa enunciar a crise ambiental como a mais vigorosa expressão da crise da Modernidade, colocando em questão os atuais padrões civilizacionais. Na contemporaneidade, quando os problemas produzidos pela devastação dos ecossistemas se tornam globais, a crise ambiental dissolve as fronteiras rígidas da Modernidade e a natureza invade a linha moderna demarcatória da separação com o campo da cultura.

\footnotetext{
${ }^{22}$ Para Fukuyama (1992), o surgimento das lutas que reivindicam direitos particulares em contraposição aos direitos universalizáveis da Modernidade é entendido como o "fim da História", que tem como centro a luta de classes e a polarização capitalismo ou socialismo.
} 


\section{Considerações finais}

As formações discursivas sobre a desordem ecológica da biosfera veiculadas na mídia também podem ser interpretadas como uma produção de sentido que expressa não só o problema da destruição da natureza e a degradação dos estilos de vida urbanos e rurais, mas, principalmente, os riscos de uma catástrofe ecológica global que ameaça a sobrevivência da humanidade e do planeta. Por um lado, a questão ecológica ganha visibilidade midiática a partir de duas ordens do discurso que se tornaram hegemônicas no campo jornalístico: vinculada ao passado, uma visão de preservação da natureza por ser um espaço do sagrado e de conservação da tradição; na perspectiva do futuro, uma visão de gerenciamento eficaz dos ecossistemas pela eficácia da ciência e eficiência da tecnologia.

Por outro, os riscos globais que inauguram a era das "três ecologias" enunciada por Guattari (1990) - são também demarcações distintivas dos discursos jornalísticos presentes na mídia, inflados por um dever moral centrado no medo em relação às catástrofes globais e aos desequilíbrios planetários.

Resta ainda uma questão teórica: afinal, o princípio da responsabilidade (JONAS, 2006) é um dever moral ou uma opção ética? Os riscos globais que inauguram a era das "três ecologias" (GUATTARI, 1990) são também demarcações distintivas dos discursos jornalísticos presentes na mídia, inflados por um dever moral centrado no medo em relação às catástrofes globais e aos desequilíbrios planetários. As mensagens jornalísticas, entretanto, constroem uma ordem discursiva sobre os problemas ambientais, vinculando essa temática ao princípio da responsabilidade, no qual a ação da sociedade acaba sendo impulsionada por uma pedagogia política centrada no sentimento do medo coletivo.

Nessa perspectiva, a crise ambiental recoloca, na cena teórica, a natureza como uma questão para o pensamento: a ecologia emerge como um campo de saber e um problema ético-político, tornando-se, ao mesmo tempo, um ramo especializado da ciência e uma das vertentes do movimento social contemporâneo de maior visibilidade na mídia. O movimento ecológico pode ser situado como um movimento social típico da cultura de massa, pois as inúmeras denúncias de desastres ecológicos e manifestações em defesa do meio ambiente, veiculadas incessantemente pelos meios de comunicação de massa, acabaram por produzir uma sensibilidade ecológica que ultrapassou as fronteiras do próprio movimento. 
A dupla perspectiva da ecologia - um saber científico e uma das vertentes constituintes dos novos movimentos sociais - aponta que estão em jogo valores contraditórios e a crise ambiental torna-se, na avaliação dos ecologistas, oportunidade para a construção de uma proposta ética que possibilite a transformação histórica. Esta ética, todavia, não pode ser construída a partir do medo da catástrofe ecológica global conforme fazem os discursos jornalísticos veiculados nos meios de comunicação de massa -, já que tais formações discursivas têm, como imperativo moral, a problemática da sobrevivência da humanidade.

Talvez a ultrapassagem de uma heurística do medo, presente nas formações discursivas contemporâneas sobre o meio ambiente - inclusive na cobertura jornalística de temas ambientais -, possa ser dada pela proposta lançada por Michel Serres (1991), que funda uma ética ecológica sobre o amor. Uma heurística do amor, aponta Leis (1999, p. 218), pode ter condições de superar o impasse de uma ética formulada a partir do princípio de responsabilidade no qual o medo é imperativo para demandar a tomada de atitude frente aos problemas ambientais. Para ultrapassar essa heurística do medo de herança hobbesiana, Serres propõe ampliar o campo da ética para realizar plenamente o contrato natural, indo além dos interesses exclusivamente humanos das éticas antropocêntricas.

Pesquisar a presença de uma heurística do amor nos discursos jornalísticos formulados por organizações não-governamentais ecologistas é uma proposta para outros trabalhos que visem avançar em relação a atual etapa do jornalismo ambiental produzido pela grande imprensa. Pode ser que essas novas experiências jornalísticas consigam romper com o discurso centrado em uma heurística do medo, tal como exemplificado nos dois jornais diários cariocas estudados aqui nesse ensaio.

\section{Referências}

AGUIAR, L. A. de. A cultura de massa e a crise ecológica global na mídia: uma crítica ao princípio de responsabilidade. In: CONGRESSO BRASILEIRO DE CIÊNCIAS DA COMUNICAÇÃO, 27., 2004, Porto Alegre. Anais... São Paulo: Sociedade Brasileira de Estudos Interdisciplinares de Comunicação, 2004. 1 CD.

O discurso ecológico no contexto das ameaças artificiais. In: CONGRESSO BRASILEIRO

DE CIÊNCIAS DA COMUNICAÇÃO, 26., 2003, Belo Horizonte. Anais... São Paulo: Sociedade Brasileira de Estudos Interdisciplinares de Comunicação, 2003. 1 CD. 
O discurso da sustentabilidade: uma genealogia. In: SCHAUN, A.; UTSUNOMIYA, F. (Orgs.). Comunicação e sustentabilidade: conceitos, conceitos e experiências. Rio de Janeiro: E-papers, 2010. p. 51-68.

BECK, U. Risk society: towards a new modernity. Londres: Sage, 1992.

Ecological politics in an age of risk. Cambridge: Polity, 1994.

BULL, D.; HATHAWAY, D. Pragas e venenos: agrotóxicos no Brasil e no Terceiro Mundo. Petrópolis: Vozes, 1986.

CARSON, R. Primavera silenciosa. São Paulo: Melhoramentos, 1964.

COMISSÃO MUNDIAL SOBRE O MEIO AMBIENTE E DESENVOLVIMENTO. Nosso futuro comum. Rio de Janeiro: Fundação Getúlio Vargas, 1988.

CRESPO, S. O ecologismo e a desencarnação do mal na sociedade contemporânea. In: BIRMAN, P.; NOVAES, R. (Orgs.). O mal à brasileira. Rio de Janeiro: EdUERJ, 1997. p. 196-213.

FOUCAULT, M. As palavras e as coisas: uma arqueologia das ciências humanas. São Paulo: Martins Fontes, 1999.

A arqueologia do saber. Rio de Janeiro: Forense Universitária, 1997.

A ordem do discurso. São Paulo: Loyola, 1996.

História da sexualidade I: a vontade de saber. Rio de Janeiro: Graal, 1980.

_. Microfísica do poder. Rio de Janeiro: Graal, 1979.

__. Vigiar e punir: o nascimento da prisão. Petrópolis: Vozes, 1977.

FUKUYAMA, F. O fim da História e o último homem. Rio de Janeiro: Rocco, 1992.

GUATTARI, F. As três ecologias. Campinas: Papirus, 1990.

JONAS, H. O princípio responsabilidade: ensaio de uma ética para a civilização tecnológica. Rio de Janeiro: EdPUC-Rio/Contraponto, 2006.

LEIS, H. A Modernidade insustentável: as críticas do ambientalismo à sociedade contemporânea. Petrópolis: Vozes, 1999.

MEADOWS, D.H. et al. Limites do crescimento. São Paulo: Perspectiva, 1973.

MILBRATH, L. Environmentalists: vanguard for a new society. Albany: State University of New York Press, 1984.

MORIN, E.; KERN, A. B. Terra-pátria. Porto Alegre: Sulina, 1995.

PRIGOGINE, I. O fim das certezas: tempo, caos e as leis da natureza. São Paulo: EdUNESP, 1996.

RODRIGUES, A. D. Estratégias da comunicação. Lisboa: Presença, 1997. 
ROSZAK, T. Person-planet. The creative disintegration of industrial society. Londres: Granada Publishing, 1981.

SADER, E. A ecologia será política ou não será. In: GOLDENBERG, M. (Org.). Ecologia, ciência e política. Rio de Janeiro: Revan, 1992. p. 135-142.

SERRES, M. O contrato natural. Rio de Janeiro: Nova Fronteira, 1991.

VARELA, F. Autonomie et connaissance: essai sur le vivant. Paris: Seuil, 1989.

VIOLA, E.; LEIS, H. Desordem global da biosfera e nova ordem internacional: o papel organizador do ecologismo. In: LEIS, H. (Org.). Ecologia e política mundial. Petrópolis: Vozes, 1991. p. 23-50. 